\title{
Two new species of Fedrizziidae (Acari: Mesostigmata) from Australian passalid beetles (Coleoptera: Passalidae)
}

OWEN D. SEEMAN

Queensland Museum, PO Box 3300, South Brisbane 4101, Qld, Australia.E-mail: owen.seeman@qm.qld.gov.au

\begin{abstract}
Two new species of Neofedrizzia, Neofedrizzia susanae sp. nov. and Neofedrizzia jeffi sp. nov., are described from the passalid beetle Aulacocyclus teres (Percheron) collected in southeast Queensland, Australia.
\end{abstract}

Key words: Taxonomy, Antennophorina, Fedrizzioidea, new species, host-associations

\section{Introduction}

Fedrizziid mites are a fairly uniform group of brown, glossy mites found almost exclusively on passalid beetles ("bess-bugs", "family beetles") in Australia and the South-east Asian region (Seeman 2007). Only adult mites are found on beetles; the immature life stages are free-living in the galleries of their host beetles. Adult mites feed on nematodes and use their long filamentous cheliceral excrescences to scavenge internal fluids from the bodies of dead arthropods (Seeman 2000).

The family currently comprises 32 species in the genera Fedrizzia (11 spp.), Neofedrizzia (20 spp.), and Parafedrizzia (1 sp.). In this work, I describe another two species of Neofedrizzia collected from Aulacocyclus teres (Percheron), a passalid species hitherto unexamined for mites.

\section{Materials and methods}

Adult beetles were captured at a light trap, with one exception, and placed into individual vials of 75\% ethanol. Beetles were identified with Dibb (1938) and Seeman (2002). Mites were removed from the ethanol, cleared in Nesbitt's fluid, and slide-mounted in Hoyer's medium. Measurements and illustrations were made with the aid of a Nikon Eclipse 80i microscope equipped with DIC and a drawing tube. Morphology and setal designations follow those used in Seeman (2007). Measurements are in micrometres and are greatest lengths or widths of the relevant structure. Collection abbreviations are used for the Queensland Museum, Brisbane (QM) and the Australian National Insect Collection, Canberra (ANIC). 


\section{Taxonomy}

\section{FEDRIZZIIDAE Trägårdh, 1937}

\section{Neofedrizzia Womersley, 1959}

Neofedrizzia Womersley, 1959, p. 30. Type species: Neofedrizzia gayi Womersley, 1959, by original designation.

Diagnosis as of Seeman (2007).

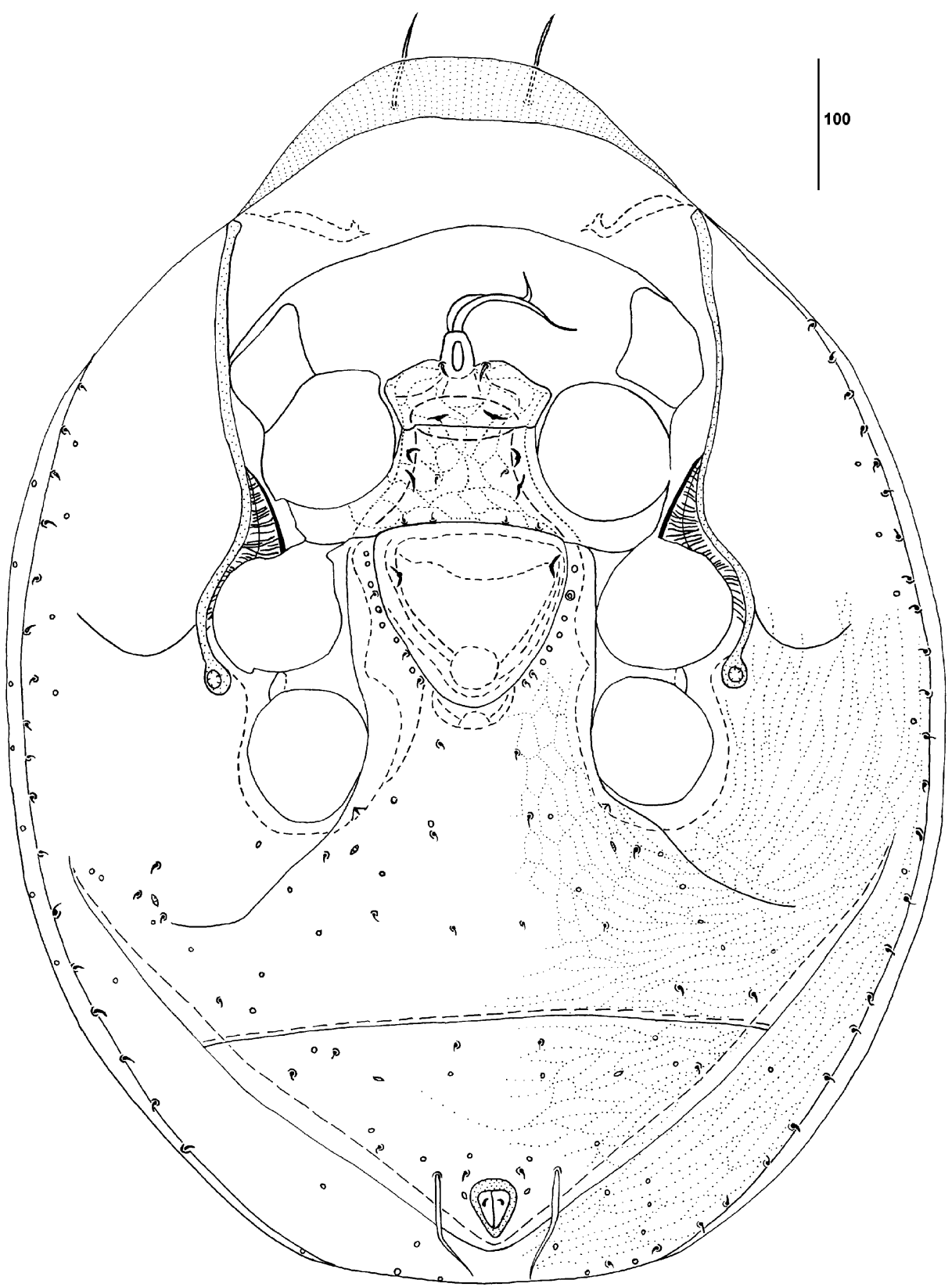

FIGURE 1. Female Neofedrizzia susanae sp. nov., venter. 


\section{Neofedrizzia susanae Seeman sp. nov. (Figs 1-4)}

Type specimens: Holotype, F, AUSTRALIA: Queensland: Dayboro, 9 January 2005, S. Wright, ex Aulacocyclus teres collected at light trap (QMS83938). Paratypes, 4 F, 4 M, same data as holotype (QMS83940-83946). 1 M, same data except collected 20 January 2004 (QMS83939). 1 F, same data except collected 7 February 2003 (QMS83947). Holotype and paratypes deposited in QM, except 1 female (same data as holotype) deposited in ANIC. Two host specimens deposited in QM (T156261156262).

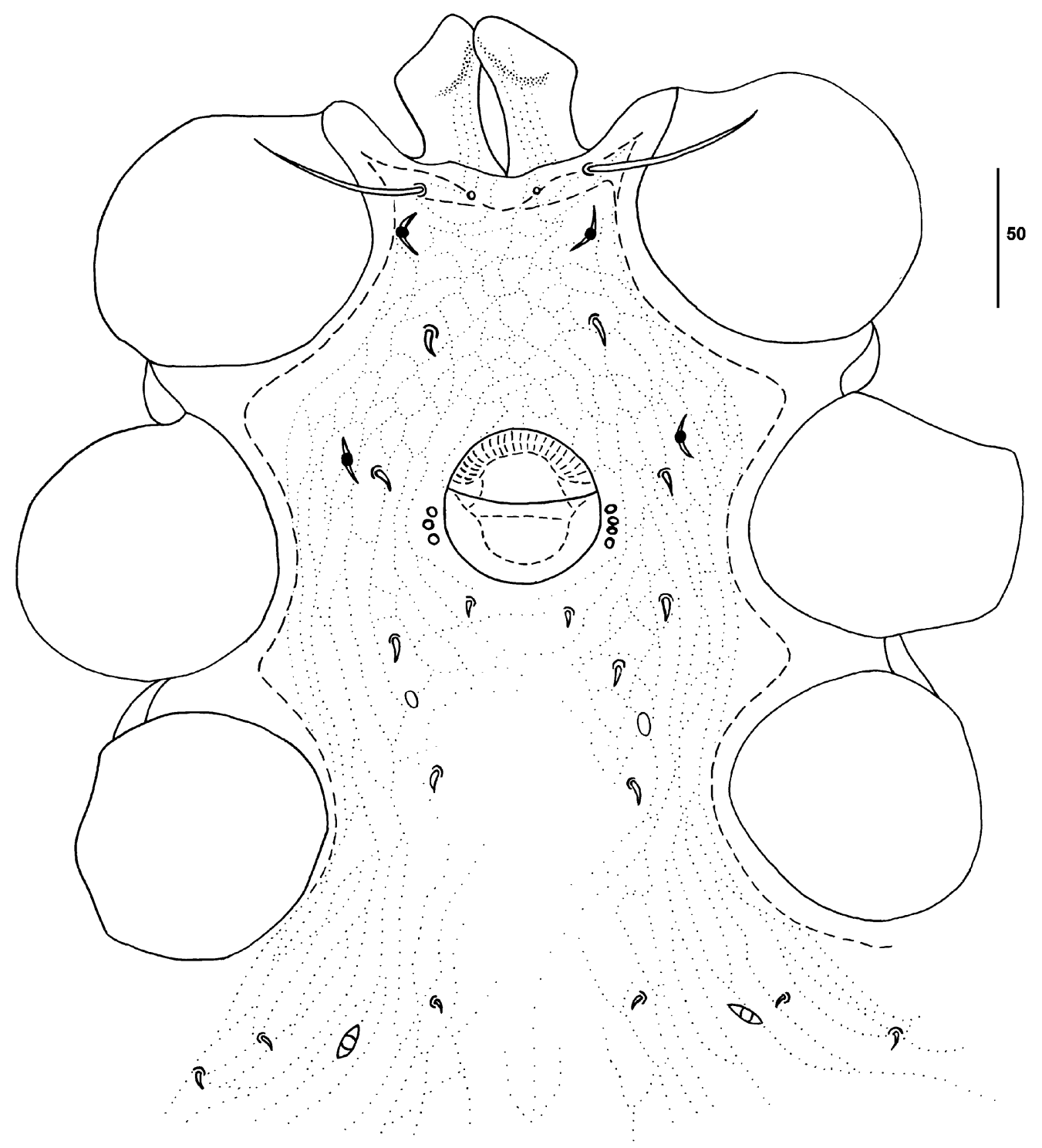

FIGURE 2. Male Neofedrizzia susanae sp. nov., sternogenital region.

Diagnosis. Idiosoma 830-925 long; anterior hyaline projection does not extend past CxI; exopodal patterning between CxII-III striped; pedofossae III present, IV absent; seta $h l$ with 6-7 barbs; distal spine-like process on palp femur minute or absent; chelicerae with a filamentous 
excrescence, a short serrated blade and a ribbon-like excrescence; femur III and IV with large lamellae. Female: sternal shield reticulate; seta stl 23-40 long, shorter than or subequal to base of tritosternum; seta st 2-15 long, st 3 long, st 4 minute; sternogynial shield smooth, anterior margin straight. Male: tetartosternum absent, presternal processes weakly articulated with sternoventral shield, symmetrical, with inner margin much longer than outer margin; sternoventral shield (anterior of genital opening) reticulate; seta st 1 50-55 long; genital opening placed between CxII-III, flanked by $6-9$ pores.
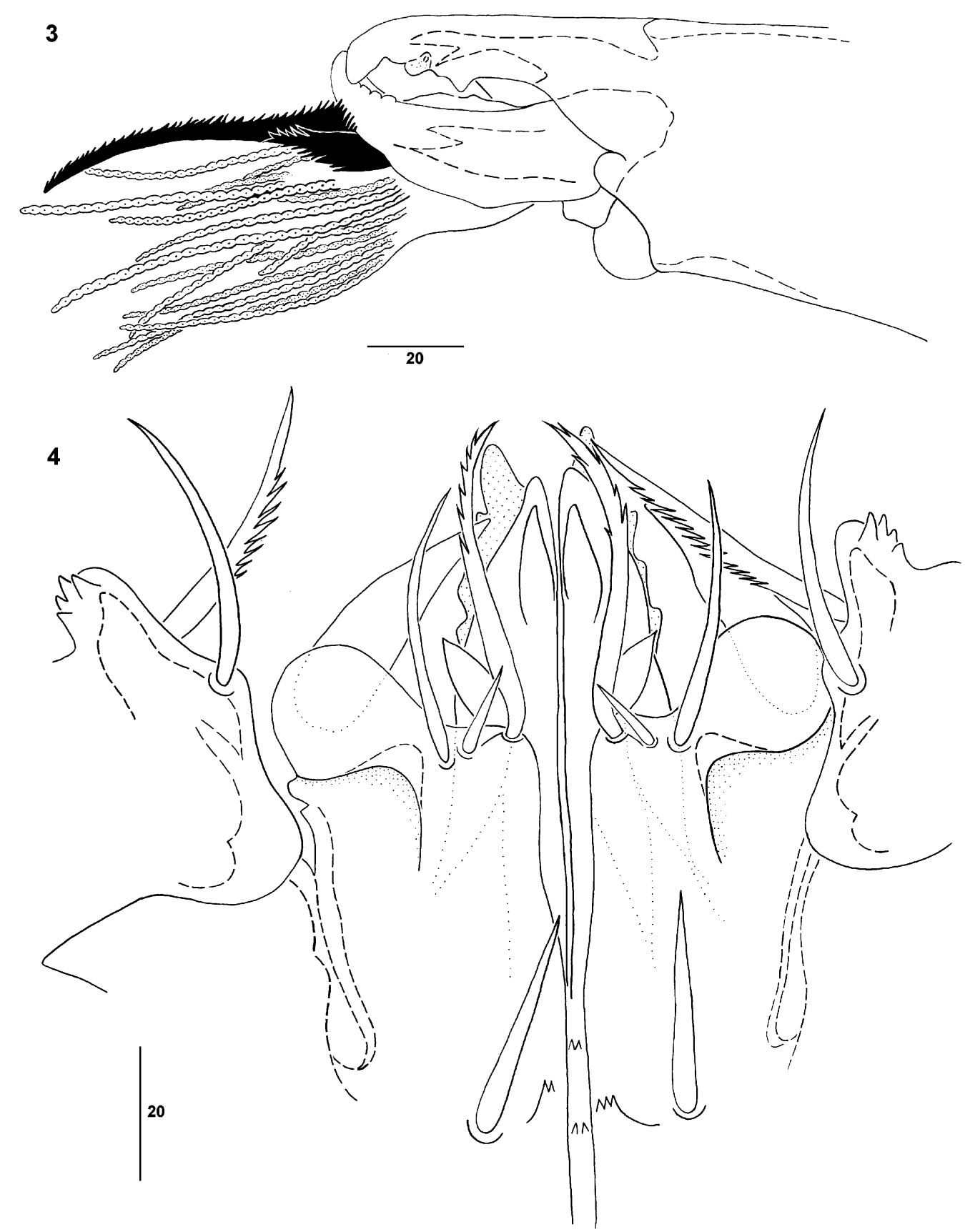

FIGURES 3-4. Male Neofedrizzia susanae sp. nov. 3, chelicera; 4, palp trochanter and hypostome. 
Description. Female: Idiosoma 890-925 long, 695-710 wide; anterior hyaline projection with 1 pair barbed setae 45-53 long. Tritosternum base 40-45 long, 28-32 wide. Tetartosternum crownshaped, reticulate, 47-54 long, 125-138 wide, st 1 smooth, 23-40 long. Sternal shield reticulate, st2 smooth, 5-15 long, st 5 long, st4 minute. Sternogynial shield 119-125 long, 143-145 wide, smooth, with 5-6 setae and 13-17 pores flanking shield. Ventral shield with lineate reticulation laterally, smooth medially; 1 pair of large semi-circular pores posteromedially of CxIV, 1 pair of eye-like pores, 7-8 pairs of small round pores, and 7-9 pairs of small ( $2-5$ long) setae. Ventrianal shield 160170 long, 375-415 wide, with lineate reticulation, paranal setae 65-90 long, other setae minute; anterolateral corner of ventrianal shield not fused with ventral shield. Marginal shield with lineate reticulation. Pedofossae III and CxIV-marginal suture present.

Legs. TrI with seta $p v 1$ as thick as seta $a v 1$. FeI with seta $p v 3$ longer and thicker than setae $p v 1$ and $p v 2$. FeII with ventral lamella, seta $a d l$ barbed and thickened. GeII with seta $a d 3$ thickened and $p d 3$ normal. FeIII with lamella, expanded distal to $a v 1$, seta $p v 1$ spine-like. GeIII with seta $p d 2$ weakly spine-like. FeIV with lamella, expanded distal to $a v 1$, seta $p v 1$ thick, spine-like, seta $a d 2$ thickened, seta $p d 2$ in line with seta $a d 2$. TaII with seta $a v 2$ and $a v 3$ spine-like, 23-25 long. TaIIIIV with seta $a v 2$ spine-like, shorter than seta $a v 3$. Legs II-IV otherwise with setiform $a d$ and $p d$ setae.

Gnathosoma. Seta $h l$ curved, not broad ( 2 wide), with 6-7 barbs, 63-73 long, distance between $h 1-h 1$ 8-9; $h 2$ barbed, 40-45 long; $h 312$ long, posterolaterad $h 2$; palpcoxal seta 17-20 long. Corniculi not on tubercles. Palp trochanter with blunt process and process with 4-5 denticles, seta avl with many barbs, seta $a v 2$ with few barbs. Palp setation, from trochanter, 2-5-7-15-16, apotele 2-tined. Chelicera, fixed digit 165 long, movable digit 68 long; fixed digit with 2 large and 1 minute subapical tooth; excrescences consist of a large brush-like filamentous process, a small serrated blade, and a ribbon-like process with a crenate margin that extends well beyond end of chelicera.

Male: Idiosoma 830-875 long, 640-695 wide. Tritosternum base broad, 65-72 long, 60-68 wide. Presternal processes symmetrical, 50-58 long, directed anteriorly, with outer margin shorter, 30-33 long; anteromedial margin with dorsal concavity, ventral surface with weak reticulation. Seta st 1 barbed, 50-55 long, st2-4 2-5 long. Sternal shield anterior of genital opening reticulate. Genital opening 53-60 long, 55-58 wide, with 6-9 large pores laterad the opening. Large lamellae on CxI. Seta $h 3$ posterolaterad $h 1$, just anterior of $h 2$. Palpcoxal seta 32-35 long.

Etymology. It is a pleasure to name this species for Susan Wright, my friend and colleague who collected the beetle from her home.

\section{Neofedrizzia jeffi Seeman sp. nov. (Figs 5-6)}

Type specimens: Holotype, F, AUSTRALIA: Queensland: Dayboro, September 2003, S. Wright, ex Aulacocyclus teres collected at light trap (QMS 83948). Paratypes, 2 M, same data as holotype (QMS83949-83950). $1 \mathrm{~F}$, same data as holotype except collected 11 January 2004, ex drowned $A$. teres, mites in water (QMS 83951). 3 F, 2 M, same data as holotype except collected 9 January 2005 (QMS 83952, 83953, 83955, 83956). 1 M, same data as holotype except collected 7 February 2003 (QMS 83957). Holotype and paratypes deposited in QM, except 1 female deposited in ANIC. One host specimen deposited in QM (T156263).

Diagnosis. Idiosoma 810-925 long; anterior hyaline projection does not extend past CxI; exopodal patterning between CxII-III striped; pedofossae III present, IV absent; seta $h l$ with 6 barbs; distal spine-like process on palp femur minute or absent; chelicerae with a filamentous excrescence, a short serrated blade and a ribbon-like excrescence; femur III and IV with large lamellae. Female: sternal shield reticulate; seta st 148 long, length subequal to base of tritosternum; 
seta st 35 long, smooth, setae st3-4 minute; sternogynial shield smooth, anterior margin straight. Male: tetartosternum absent, presternal processes articulated with sternoventral shield, symmetrical, with tips pointed inwards and narrow anterior concavity; sternoventral shield (anterior of genital opening) reticulate; seta st1 40-48 long; genital opening placed between CxII-III, flanked by 4-5 pores.

Description. Female: Idiosoma 810-840 long, 645-670 wide; anterior hyaline projection with 1 pair barbed setae 51-60 long. Tritosternum base 38-43 long, 30-35 wide. Tetartosternum crownshaped, reticulate, 45 long, 115-123 wide, st1 smooth, 45-48 long. Sternal shield reticulate, st 2 smooth, 33-35 long, st3-4 minute. Sternogynial shield 103-108 long, 130-136 wide, smooth, with 5-6 setae and 2 pores flanking shield. Ventral shield with lineate reticulation laterally, smooth to weakly reticulate medially; 1 pair of large semi-circular pores posteromedially of CxIV, 1 pair of eye-like pores, 5 pairs of small round pores, and 5 pairs of minute setae. Ventrianal shield 160-170 long, 370-400 wide, with lineate reticulation, paranal setae 70-83 long, other setae minute; anterolateral corner of ventrianal shield not fused with ventral shield. Marginal shield with lineate reticulation. Pedofossae III and CxIV-marginal suture present.

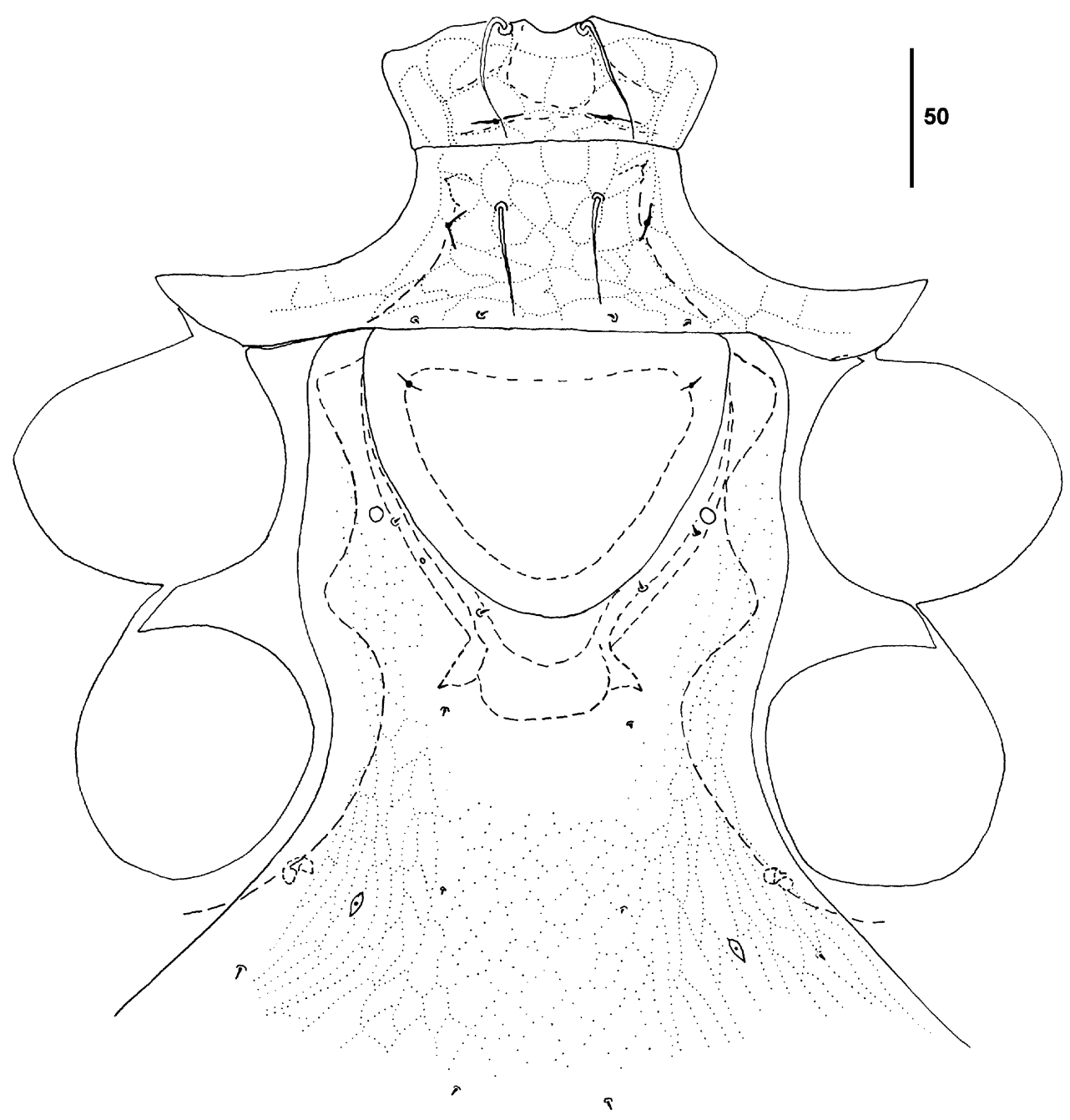

FIGURE 5. Female Neofedrizzia jeffi sp. nov., sternogenital region. 


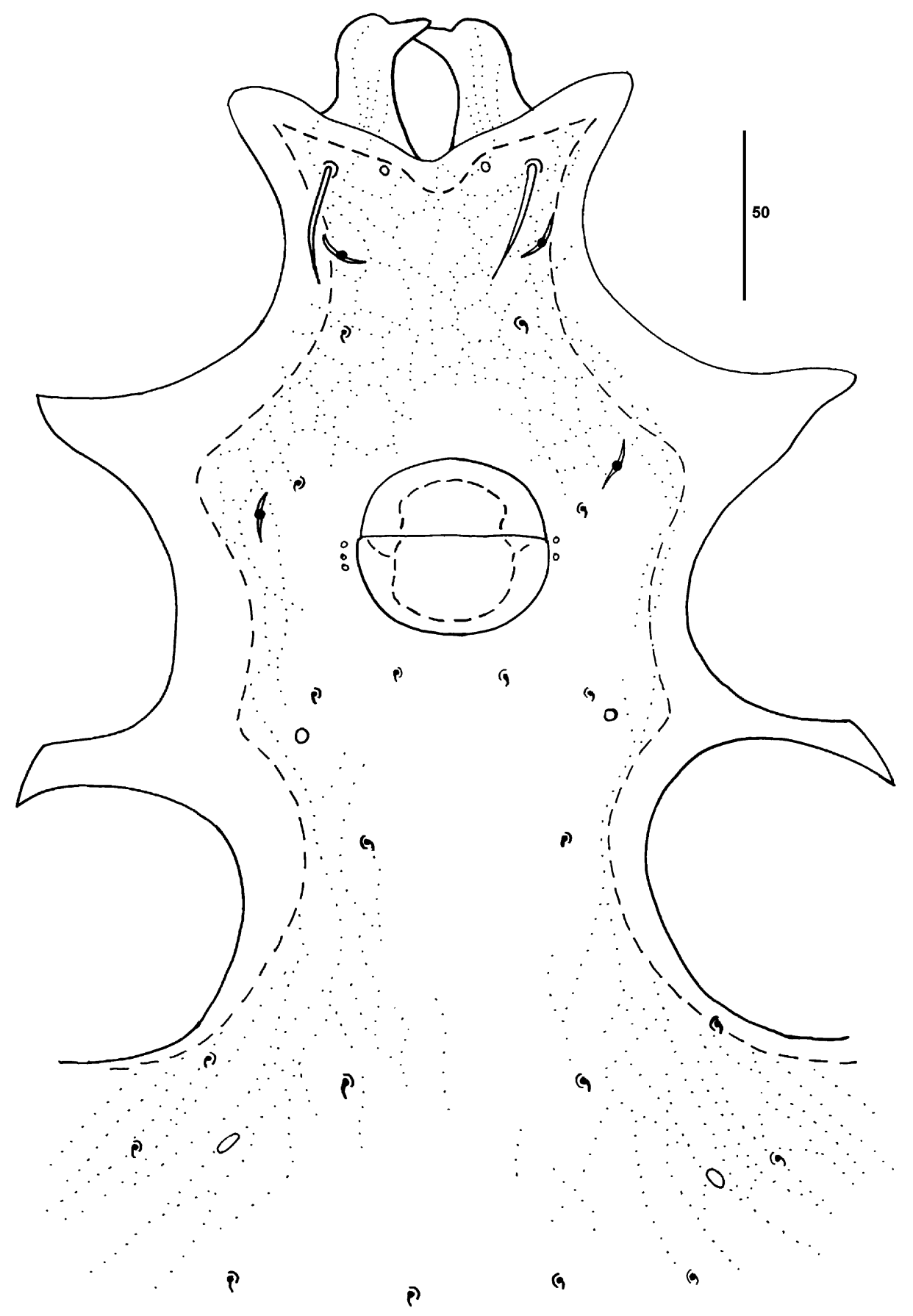

FIGURE 6. Male Neofedrizzia jeffi sp. nov., sternogenital region.

Legs. Same as for N. susanae.

Gnathosoma. Seta $h l$ curved, not broad ( 2 wide), with 6 barbs, 60-63 long, distance between $h 1-h 1$ 10-11; $h 2$ weakly barbed, 45 long; $h 312-15$ long, posterolaterad $h 2$; palpcoxal seta $13-15$ long. Corniculi not on tubercles. Palp trochanter with blunt process and process with $4-5$ denticles, 
seta $a v 1$ with many barbs, seta av2 with few barbs. Palp setation, from trochanter, 2-5-7-15-16, apotele 2-tined. Chelicera, fixed digit 165-168 long, movable digit 76-78 long; fixed digit with 2 large and 1 minute subapical tooth; excrescences consist of a large brush-like filamentous process, a small serrated blade, and a ribbon-like process with a crenate margin that extends well beyond end of chelicera.

Male: Idiosoma 840-925 long, 615-710 wide. Tritosternum not seen. Presternal processes symmetrical, 40-50 long, with tips pointed sharply inwards and a narrow anterior concavity, giving the impression of bird-heads pointing together; anteromedial margin with dorsal concavity, ventral surface with weak reticulation. Seta stl barbed, 40-48 long, st2-4 2-5 long. Sternal shield anterior of genital opening reticulate. Genital opening 58-63 long, 60-68 wide, with 4-5 large pores laterad the opening. Large lamellae on Cx I. Seta $h 3$ posterolaterad $h l$, just anterior of $h 2$. Palpcoxal seta 30-35.

Etymology. It is a pleasure to name this species for Jeff Wright, my friend and colleague, and partner of Susan, who collected the beetle from their home.

\section{Discussion}

Female and male mites were unusually difficult to match, as both species overlap in size and occurred on the same host specimens. I used the number of pores flanking the genital opening as the main indicator for matching sexes, with female and male $N$. susanae possessing more pores (13-17 and 6-9 pores, respectively) than female and male $N$. jeffi ( 2 and 4-5 pores, respectively).

Both species are easily accommodated in the key to Neofedrizzia published by Seeman (2007). For female mites, at couplet 8 , insert the following couplet and modify other numbers accordingly:

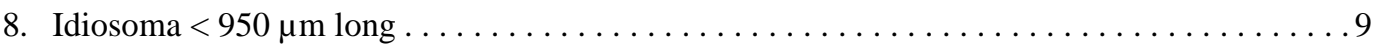

- Idiosoma $>1000 \mu \mathrm{m}$ long .......................................

9. Sternogynial shield flanked by 13-17 pores; setae st 1 23-40 long, st2 5-15 long, st3 5 long. Idiosoma 890-925 long. Australia: Southeast Queensland. . . . . Neofedrizzia susanae sp. nov.

- Sternogynial shield flanked by 2 pores; setae st 45-48 long, st 2 33-35 long, st3 minute. Idiosoma 810-840 long. Australia: Southeast Queensland. . . . . . . . Neofedrizzia jeffi sp. nov.

For male mites, at couplet 11 , insert:

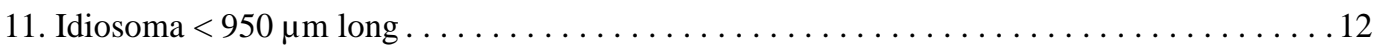

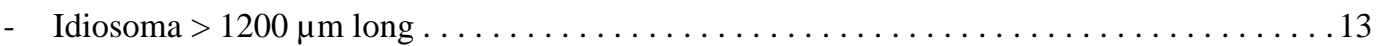

12. Presternal shields with inner margins roughly parallel to each other and longer than outer margin. Idiosoma 830-875 long. Australia: Southeast Queensland...... Neofedrizzia susanae sp. nov.

- Presternal shields with inner margins curved, their tips pointed sharply together; inner margin subequal to outer margin. Idiosoma 840-925 long. Australia: Southeast Queensland . . . . . . . . Neofedrizzia jeffi sp. nov.

\section{Acknowledgements}

I am especially grateful for the drawings by Rebekah Wruck, a volunteer scientific illustrator at the Queensland Museum, who drew all illustrations except the female of $N$. jeffi. 


\section{References}

Dibb, J.R. (1938) Synopsis of Australian Passalidae (Coleoptera). Transactions of the Royal Entomological Society of London, 87, 103-124.

Seeman, O.D. (2000) The immature life stages of the Fedrizziidae (Mesostigmata: Fedrizzioidea). Acarologia, $41,39-52$.

Seeman, O.D. (2002) Mites and passalid beetles: diversity, taxonomy and biogeography. PhD thesis. The University of Queensland. $339 \mathrm{pp}$.

Seeman, O.D. (2007) Revision of the Fedrizziidae (Acari: Mesostigmata: Fedrizzioidea). Zootaxa, 1480, 1-55.

Trägårdh, I. (1937) Zur systematik der Mesostigmata. Arkiv för Zoologi, 29, B(11), 1-8.

Womersley, H. (1959) Some Acarina from Australia and New Guinea paraphagic upon millipedes and cockroaches and beetles of the family Passalidae. Transactions of the Royal Society of South Australia, 82, 1154.

Accepted by A. Baker: 27 Apr. 2009 